\title{
Challenges and Innovative Solutions in Urban Rail Transit Network Operations and Management: China's Guangzhou Metro Experience
}

\author{
Lin $\mathrm{He}^{1} \cdot$ Qiangsheng Liang ${ }^{1} \cdot$ Siyuan Fang ${ }^{1}$
}

Received: 16 December 2015/Revised: 10 April 2016/Accepted: 13 April 2016/Published online: 5 May 2016

(C) The Author(s) 2016. This article is published with open access at Springerlink.com

\begin{abstract}
Urban rail transit operations have changed from a single line to a multiline network. The network operations have undergone quantitative and qualitative changes, and operations management is facing rapid internal and external changes. Using the Guangzhou Metro network operation practices as a case study, this paper first systematically analyzes the features of the operation scale, the proportion of urban mass transit, the surge in public demand, the security of the operational service capacity, reforms to the operation governance structure, the highspeed expansion of staff, and the development of knowledge and skills in urban mass transit networks. The paper then proposes several responses to the challenges that such networks face; for example, this paper proposes creating an innovative network operations management system, strengthening the management foundation, creating plans to promote operation capacity, enhancing security risk management and equipment quality management, developing a crisis public relations response, and applying information technology. In addition, this paper systematically describes countermeasures for multiline network operations, such as developing a management mechanism for network operations, actively cultivating staff skills, creating innovative transport organization models to enhance operational capacity, establishing a production service assessment system to continuously improve the level of transportation service, establishing a quantifiable
\end{abstract}

Qiangsheng Liang

liangqiangsheng@gzmtr.com

1 Guangzhou Metro Group Co., Ltd., Guangzhou 510335, China

Editor: Xuesong Zhou safety assessment system and equipment quality index model, strengthening quality controls for security and equipment, extensively using information technology to ensure the health of the urban mass transit network operation, and implementing sustainable development measures.

Keywords Urban rail transit - Network operations . Innovation systems and mechanisms - Passenger flow forecasting · Transport organization optimization - Safety and emergency systems · Operating information · Lean management $\cdot$ Knowledge inheritance $\cdot$ Guangzhou metro

\section{Characteristics of Network Operations}

Currently, there are a variety of definitions and interpretations of urban transit network operations based on the number of open lines, the total route mileage, or the passenger volume. These different standards reflect certain operational characteristics, but more comprehensive measures are necessary to meet specific requirements in different cities. Usually, the following three characteristics of operations are considered as network operation:

1. Regional coverage With the increasing urban rail construction, line mileage has increased rapidly to form a basic network-level urban rail system that provides preliminary connectivity and mobility in major areas of some cities in China.

2. Station location Optimized transit station location could provide high accessibility with a wide coverage area for travelers, especially in the core areas of cities. The general preferred coverage diameter should be limited to within $2 \mathrm{~km}$. 
3. Percentage of urban rail transit use among all travel modes Rail transit has been a major travel mode in urban areas. Its use among all modes of travel has reached more than $30 \%$ and has been over $50 \%$ in some urban core areas [1-5].

\section{Challenges of Network Operations}

The scale of rail lines in some urban rail companies has changed from a single line to a network with multiple lines. In future, more companies will face the challenges of network-level operations. How to address those large travel demands and improve service quality and efficiency is an important issue.

\subsection{Increasing Public Travel Demand Leads to Great Challenges to Operations and Management}

With the ongoing large-scale urban rail construction, the accessibility of urban rail has undergone obvious improvements. Because of its advantages in safety, punctuality and speed, urban rail transit has become an indispensable mode of travel. As a result, citizens have increased their demands for higher-quality service. In addition, network-level rail operations require more robust control because challenges along one small part of the line can have a widespread impact on the whole transit network. In addition, the increased concern among travels means that a small operations error can attract a great deal of public attention, and the negative impacts can be magnified by internet exposure or cell phone networks if issue is not properly addressed in a timely manner [6-8].

\subsection{Inaccurate Travel-Demand Forecasting Causes Insufficient Supply}

The existing passenger forecasting method only considers travel demands along the single line being planned for construction. However, in practice, the demand areas of new lines within a transit rail network are far greater than those of a single line. The travel demands for new lines interacts with previous demands and potential new demands arising from the opening of new lines, which makes forecasting the future travel demands of existing lines and future lines extremely difficult. In this study, we consider Guangzhou Metro as an example. For a long time, the average daily passenger volume of Line 1 was steady at approximately 170,000; however, after many new lines opened, the volume increased dramatically to 1.1 million. In 2013, the average daily passenger flow of Line 3 reached
1.46 million, which is $34 \%$ more than the volume that was forecast for 2017 (1.09 million). This unexpected forecasting underestimation presents great challenges for the stability and reliability of urban rail transit operations and management $[9,10]$.

\subsection{Old Management Systems Could not Satisfy Increased Network-Level Operations}

The existing management systems can barely meet the new requirements of network-level transit operation. One main reason for this mismatch is that rail system's service coverage area has undergone great changes and now covers from the core area of the cities and the suburbs, extending to satellite cities. The old management mechanism has shown strain in addressing such large-scale rail transit operations and management. The other reason is the low efficiency of detailed job specialization in light of largescale operations that require quick responses. In traditional management mode, the division of labor is based on specific job responsibilities, and the station service department and the equipment maintenance department are generally separated. Furthermore, the equipment maintenance department is divided into smaller professional divisions (e.g., the rail track, rolling stock, power supply, communication, auto fare collection system (AFC), and electronic departments). This type of division is beneficial in the early stages of a single-line operation. However, network-level operations require more collaboration among different divisions, a higher response rate, and a wider management region, and a more efficient and comprehensive management system is imperative $[11,12]$.

\section{Potential Solutions for Network Operations and Management}

The problems with and challenges to network operations can only be solved by developing new views and actions, an inevitable phase in the development of the urban rail transit industry.

\subsection{Innovation of Network Operation Systems and Mechanisms}

Urban rail transit is entering a stage of increased development as a result of changes in productivity- and production-related adjustments to network operation conditions. After 3 years of research and planning that involved the comparison and analysis of metro operation systems in domestic and foreign locations, an 
organizational revolution plan was launched in March 2013. A new management system has been established that uses "regionalization as the overwhelming majority and specialization as a supplement" to replace the previous mode of "specialization as the overwhelming majority and regionalization as a supplement." Four regional operation centers were established under the Operations Division to facilitate the incorporation of a $520-\mathrm{km}$ line into the network operations. After 1 year of implementation, this management system has demonstrated its ability to meet the network's needs $[13,14]$.

\subsubsection{Effective Allocation of Operation Management Pressure}

A suitable line length for a relatively complete operation unit is typically $90-150 \mathrm{~km}$. The four existing regional operation centers of Guangzhou Metro are now undertaking the operation of the existing network of $260 \mathrm{~km}$ and plan to oversee the operation of $520 \mathrm{~km}$ of lines in the future. Each operation center will be responsible for a reasonable area of approximately $130 \mathrm{~km}$ of lines.

The guidelines and principles for establishing this operating system can be summarized as follows: customer orientation, service to society, resource sharing, synergetic development, simplicity and efficiency, responsibility and right, overall arrangement, and moderate competition.

The organizational structure of the Operations Division of Guangzhou Metro in 2013 is shown in Fig. 1.

\subsubsection{Promoting Service Responsibility Delivered to the Primary-Level Organization}

The principal regional entity must be established and must be responsible to the primary-level organization. The regional operations center is solely responsible for service delivery. The operations center is responsible for routine management within its operation zone, including not only the station service but also all equipment maintenance and emergency responses. By optimizing the organizational structure and combining the station attendant staff with the staff responsible for maintaining passenger interface equipment, the two positions will be better coordinated. As a result, resource sharing and faster response rates will be realized, thus strengthening the collaboration between passenger service and equipment maintenance. Considering service delivery (e.g., "customer-oriented, serve society") as a starting point, the traditional boundaries of specialized departments are no longer valid; instead, each regional manager is now responsible for meeting customers' demands as quickly as possible.

Meanwhile, the reduced range of professional management for each regional operations center creates more opportunities to focus on lean management. To achieve management goals, it is necessary to strengthen the collaborative relationship between passenger service and equipment maintenance. Performance appraisals of operation centers are becoming more precise and effective and are inspiring increasing competition [15].

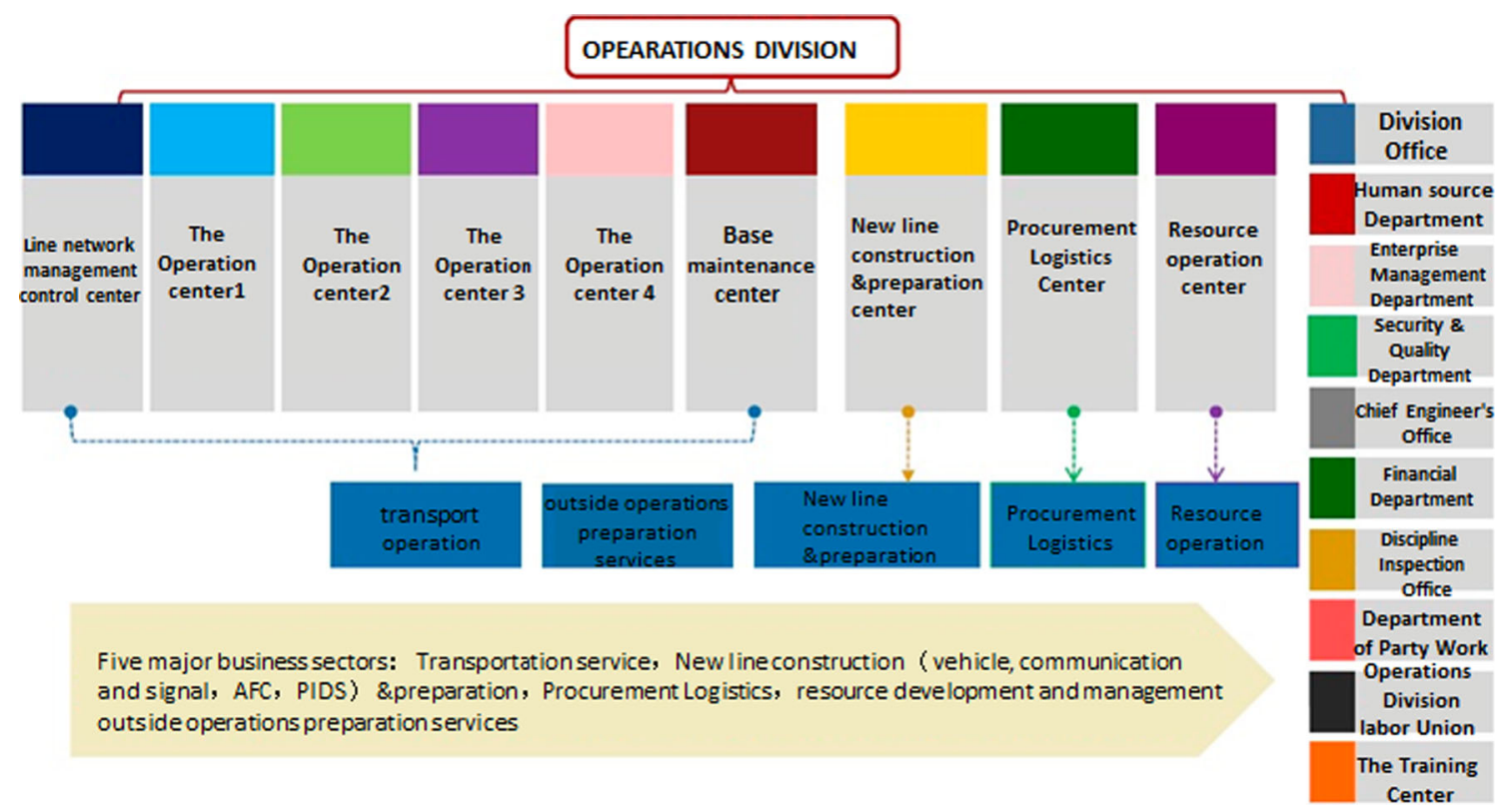

Fig. 1 Organizational structure of the operations divisions of Guangzhou metro in 2013 


\subsubsection{Creating the Mechanism for "Overall Planning and All-Round Consideration, Moderate Competition"}

The fact that each operation center generally undertakes the same work provides a foundation for benign competition. Discrepancies in transportation quality, level of service, equipment performance, and safety management among the lines can provide motivation for internal improvement and innovation among operation centers. The network management control center is responsible for unifying standards, allocating resources and coordinating dispositions. At the same time, the performance assessment system helps to moderate competition and development.

\subsubsection{Establishing a Front-End and Back-End Maintenance System}

The establishment of a front-end and back-end maintenance system enables front-end operation centers to focus on delivering services, promoting equipment maintenance based on resource sharing, and efficiently using and sharing large equipment. Such a system is conducive to the cultivation of different levels of talent and the establishment of a differentiated technology development path.

1. Promoting the integration of skills in the front-end maintenance system Regionalized operation is implemented to improve the speed of responses to passengers' service demands. The operations center, as the front-end, is responsible for the maintenance and repair of equipment and facilities. For the implementation of major integration, the major departments are classified into four categories: rolling stock, signaling, station facilities maintenance and infrastructure maintenance. A talent team with comprehensive skills is trained and organized to respond quickly to general failures and to promote the integration of similar major departments and optimize the allocation of human resources.

2. Promoting technologies in the back-end maintenance system A key technology maintenance base that covers electronic, electrical, engineering, mechanical, and inspection aspects is established to support network equipment maintenance at the back-end. Scientific research, technical renovation, large-scale component maintenance, equipment overhaul, and comprehensive monitoring of large-scale equipment are cultivated via the construction of a large test/inspection platform and testing equipment. This arrangement will also improve the ability to address comprehensive emergencies. In addition, various types of technology are being applied, and a comprehensive skilled personnel team is being formed.

\subsection{Promoting the Planning of Network Operations}

\subsubsection{Comprehensive Passenger Flow Forecasting According to Urban Development}

Rail transit passenger flow forecasting should take into account the developing trends of the future network instead of the current single line and should analyze the predicted trends of rail transit demands at the height of the urban development. The passenger flow in Guangzhou Metro was forecast by considering both construction time and the results of special passenger flow analyses of newly opened lines. For example, Line 6 opened at the end of 2013, after Guangzhou Metro had analyzed its network's total passenger flow and travel characteristics at the end of 2012.

Traditional passenger flow forecasting methods cannot reflect gradual changes in the passenger flow distribution over time and space; therefore, advanced technologies are required to construct prediction models for developing short-term and real-time passenger flow forecasts. Currently, we use a preliminary rail transit passenger-flow forecast model and an algorithm to determine the condition of network operations. This model is capable of addressing work days, holidays, and large-scale activities, and it provides data support for transportation planning and holiday operation schemes at the network level and the implementation of gradual improvement plans over different time periods $[16,17]$.

In cooperation with Beijing Jiaotong University, Guangzhou Metro is involved in an industry-university research program on a science and technology project called "The Identification of Mechanisms that Determine Passenger Flow in the Urban Rail Transit Network and the Development of the Operations Support System." The project focuses on network operations and AFC data mining. Data from multiple sources (e.g., site properties, line network topology, and train schedules) and technological applications (e.g., statistical analysis, traffic behavior analysis, data mining, and cloud computing), were used to determine the key elements that forecast rail transit network passenger flow. This research mainly includes the methods for extracting and identifying passenger flow characteristics based on AFC data, the formation mechanism of passenger flow, an urban railway passenger flow-forecasting method that satisfies a wide range of requirements and the development of the system that supports rail transit network operations [18].

\subsubsection{Innovations in Rail Operations Based on Different Situations}

To adapt to the metro construction period scheme and comprehensive passenger flow forecasting, Guangzhou 
Metro has implemented a 5-year transportation plan designed to develop transportation capacity. Furthermore, new operation strategies are being implemented to assign the available capacity to segments with high travel demands, including scheduling a short-line train during peak hours, addressing imbalanced transport operations, and designing train runs with a mix of long and short routes.

\section{Short-line trains during peak hours}

Guangzhou Metro Line 3 (including the Airport line), with its Y-shaped topology, is an important north-south traffic line in Guangzhou. The passenger flow volume has increased considerably since Line 3 opened; its full-load ratio reaches as high as $153 \%$ during peak hours. In the morning, the peak passenger flows in both directions exist primarily in the area of Tiyu Xilu station, i.e., the connection point of the ' $Y$ '. At the end of that section, the passenger flow decreases noticeably [19-23].

To cut the peak passenger flow within part of Line 3, which has a ' $\mathrm{Y}$ ' shape and moves in six directions, a scientific and reasonable method of train scheduling was proposed after the temporal and spatial passenger flow distribution was analyzed. In the morning rush hour from Tonghe to Dashi and from Dashi to Tianhe Coach Terminal, a short-line train has been added during peak hours (denoted as a red line in Fig. 2). The transport capacity of the sections from Tonghe to Tiyu Xilu and from Dashi to Tianhe Coach Terminal increased by 38 and $5 \%$, respectively.

\section{Unbalanced transport operation method}

The morning and evening rush passenger flow is notable for several lines that pass through downtown Guangzhou, which has a clear unilateral nature and centrality, and the unbalanced passenger flow coefficient of the upward and downward directions reached 2.0-4.2. Guangzhou Metro cannot meet the increasing demand by

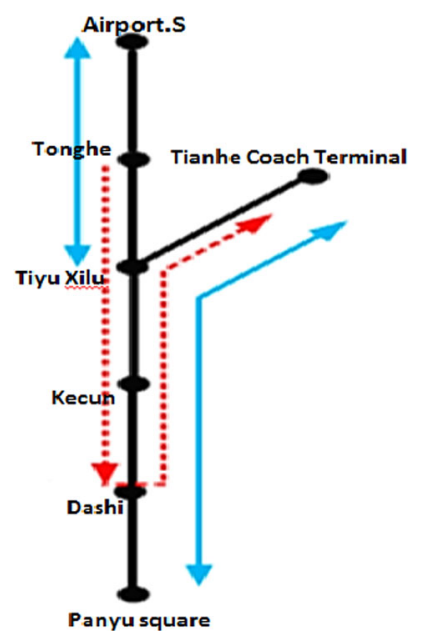

Fig. 2 Short-term peak flows for Line 3 simply adding alternative trains. Therefore, we proposed an unbalanced transport operation method to accommodate the greatest possible capacity increase during peak hours.

The unbalanced transport operation method means that under the same route conditions, some trains are shifted one direction to another (as shown in Fig. 3) or are turned back to increase the number of available trains moving in the other direction. This method is developed by analyzing the rail line directions and the time characteristics of the transport capacity distribution (the original capacity can move either forward or backward). As a result, this operation mode can distribute the limited transport capacity in a scientific and reasonable manner, meet passenger traffic demands to alleviate congestion during rush hours, and make full use of the existing transport capacity. Since 2011, Guangzhou Metro has gradually implemented this new operation mode in Lines 2, 3, 4, 5 and 6. Although the total number of available trains did not change, transport capacity was increased by more than $10 \%$, existing congestion was alleviated, and the total cost was kept within a reasonable range.

3. Trains with mixed long routing and short routing

Since December 2012, the average daily passenger flow of Line 2 has exceeded 1.2 million. The passenger volume of the area from Jiangtai Lu to Sanyuanli accounted for $70 \%$ of the total passenger flow. Based on the distribution of travel demands along the line, current transportation technology, and the full-utilization of infrastructure and equipment, we operate trains with mixed long (full) routes and short (partial) routes. This plan was implemented beginning in January 2013 (as shown in Fig. 4). To the original long route from Guangzhou South Railway Station to Jiahewanggang, we added a new short route from Jiangtai Lu to Sanyuanli (approximately $9.1 \mathrm{~km}$ ). The proportion of the full route to the short route is $2: 1$.

After this new operation mode was applied on weekdays, the transport capacity of both the upward and downward directions increased by 7 and $33 \%$, respectively after taking the long route and the short route. The congestion during peak hours is alleviated, and the train's fullload ratio is kept below $90 \%$, which represents a decrease of 6-20\% compared with the previous operation scheme. To some extent, mixed routing makes it easier for passengers to catch a train. It can also effectively reduce the number of trains on this line, thus increasing the number of trains available to Lines 1 and 8 .

\subsubsection{Increasing Transport Capacity Through Equipment Renovation}

The list of key equipment for capacity upgrades is clearly established for Guangzhou Metro based on passenger-flow 

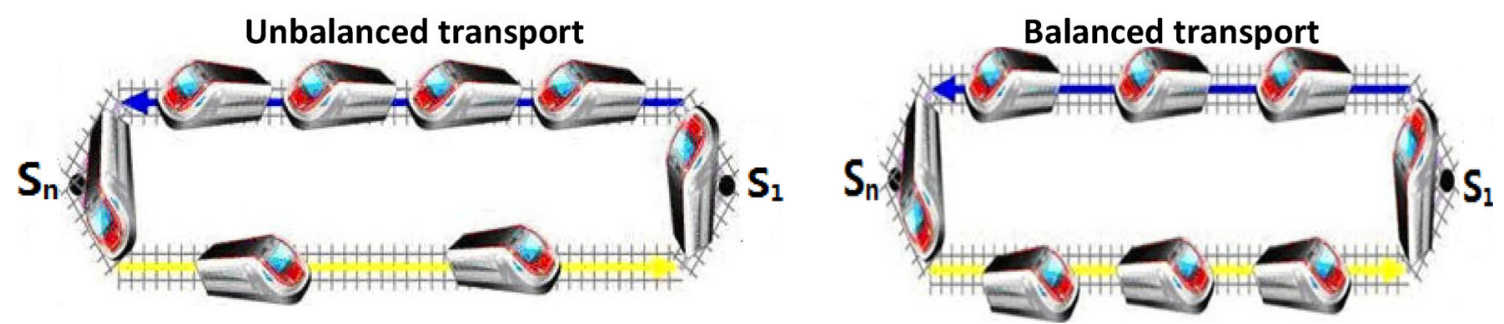

Fig. 3 Unbalanced transport operation mode

Fig. 4 Full route and partial route in Line 2

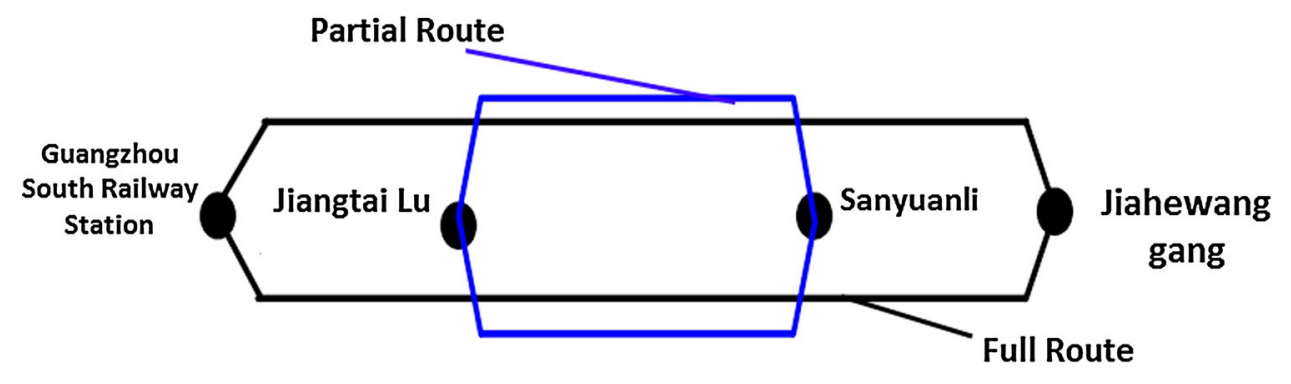

forecasting and transportation planning. With the new transport planning process, from the perspective of network-level rail operations, we predicted the future demand for trains and proposed a plan to increase train purchases to meet future needs in 2017. This plan ranges from improving transport capacity to systematically updating the signal system, the reentrant line, the vehicle depot and the other infrastructure.

\subsubsection{Establishing the Comprehensive Assessment System for Transportation Manufacturing Services}

The Comprehensive Assessment System for Transportation Manufacturing Services is an assessment index system that is closely related to the key success factors for the core strategy objectives. It is based on the principle of the balanced scorecard and uses the corporate vision, the strategic plan, the external environment, the organizational structure and the operational control goal as orienting principles. A value map is formed using four dimensions: financial, customer, internal processes and learning development.

The Comprehensive Assessment System for Transportation Manufacturing Services can be divided into a comprehensive assessment system, a transportation subsystem, a production subsystem, and a service subsystem. The output assessment results for the rail network and each region are graded according to a 4-level scale: excellent, good, qualified, and poor. According to the indicators derived from the assessment system, the "weaknesses" in transportation and production services can be identified and used to propose targeted improvement measures. When this system is implemented, the management and control of transportation production is effectively enhanced, and the traffic and service indices reach an excellent level [24-26].

\subsection{Strengthening Security Risk Management and the Control of Network Operations}

\subsubsection{Establishing a Full-Coverage Safety Management System}

A safety management system was established to achieve modular security management. The system includes eight modules: train operation, passenger transport, fire alarm, equipment, and facilities, construction operations, external environment, social security management, and ticketing revenue.

\subsubsection{Establishing a Quantifiable Safety Assessment System}

Based on the main types of operational safety risks mentioned in Guangzhou Metro's regional operations and operational safety module for managers, mathematical models of and calculation methods for a quantifiable safety assessment system were constructed. These models and methods used a single line and the operation safety management module as the basic unit of evaluation, and treated the key content and safety management efforts as assessment factors. This system realizes the quantitative analysis required for metro safety management operations and forms the Metro Operation Safety Index Assessment System. In addition, it can horizontally compare analyses of each module and the safety status of each line, and it 
refines safety management experiences, vertically analyzes the security and development trends for the quality of all equipment, and reveals the weak points of safety management.

\subsubsection{Strengthening Safety Risk Identification and Implementing Dynamic Classified Control and Prevention}

A security risk troubleshooting and summary ledger is generated and updated in real time, and all security risks are classified and graded. Meanwhile, corresponding risk control measures and emergency measures are developed in advance. In addition, the security warning and emergency platform will be developed to perform dynamic tracing, monitoring, and identity management.

\subsubsection{Improving the Emergency Management System}

All types of work in the emergency system are performed, constructed, and improved in accordance with the "one network and five databases" and "one platform" projects. The "one network" is the emergency response network; the "five databases" are the emergency regulations and plans database, the emergency specialist database, the emergency rescue team database, the emergency supplies database, and the emergency case database; the "one platform" is the security and emergency platform [27].

(1) Following the principle of "unified planning, classified guidance, centralized management and hierarchical implementation," three levels of the emergency plan system, including an overall emergency response plan, specific contingency plans and on-site disposal plans, are established. (2) A full-time rescue team and a part-time rescue team are formed according to the metro's network operation characteristics. (3) A hierarchical mechanism for emergency supply management is designed. All types of emergency supply equipment are positioned according to their related area of management responsibility and are divided into professional emergency supplies, flood control, and emergency supplies, and fire emergency supplies. (4) The external emergency links are strengthened. Currently, an emergency response mechanism has been established that includes cooperation among different departments, such as fire control, police, the community, public transport, electrical power, and the gas supply station.

\subsection{Promoting the Quality Management of Equipment at the Network Level}

Under network-level operations, the location of equipment has changed from a concentrated point to a regional area, resulting in management difficulties. The traditional "oneto-one" quality control method will undoubtedly increase management costs and cannot satisfy the requirements of big data management [28-30].

\subsubsection{Establishing an Equipment Quality Assessment Index}

The quality assessment system for rail transit equipment is based on an analytic hierarchy process and comprehensive fuzzy assessment method. It statistically classifies the faults of each subsystem and comprehensively considers the possible effects of these faults. Meanwhile, the system generates operation performance quality evaluations of all of the devices used in the network. The visual and index evaluation results of these periodic assessments allow the immediate proposal of methods for improving equipment quality in a short time.

By collecting and analyzing equipment performance data, Guangzhou Metro established an equipment quality assessment model based on the equipment failure rate (reliability) and the degree of equipment failure. Based on its own operating experience, Guangzhou Metro established reliability standards that called for assessing equipment quality on a monthly basis. These assessments strongly consider equipment failures and the events that most influenced operations. Moreover, fault impacts and reliability calculation results are analyzed using an indexing process. This process allows Guangzhou Metro to obtain quantitative and comparable results and analyze them to evaluate the performance of devices over time.

\subsubsection{Implementation of Lean Maintenance Management}

Since 2012, Guangzhou Metro has planned and implemented a lean maintenance information system (LMIS). The structure and workflow of the LMIS are shown in Fig. 5. By configuring the equipment maintenance cycles and procedures, processes, job requirements and measurement standards in the LMIS, three regulatory issues in maintenance operations are addressed: (1) Has the maintenance been performed? (2) What maintenance measures have been performed? (3) What is the result of the maintenance?

Lean maintenance quality control is realized by incorporating a revised lean business outline and process into the system. The information about the scene is recorded using photographs to further standardize staff work habits, and the recorded documents can also support inspection. The general process is as follows: (1) On a handheld terminal, the operator fills out a work order that includes measurement information regarding the procedures and uploads the data for monitoring. (2) On the handheld terminal, the maintenance operator records the actual material 


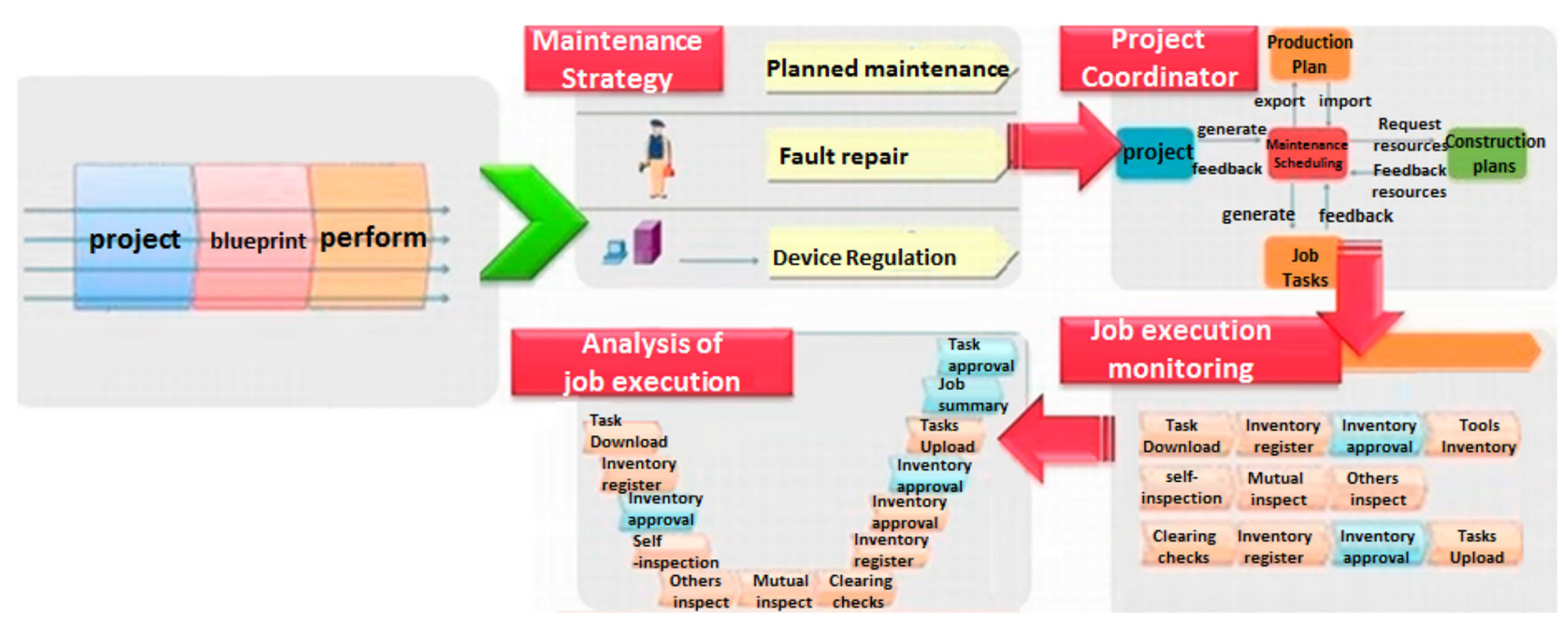

Fig. 5 Structure and workflow of the lean maintenance information system

consumption of spare device options and uploads the values to the asset management system along with the work order. (3) The LMIS strengthens the analysis of data trends regarding the equipment's state, draws attention to unusual states, and provides additional maintenance information.

Guangzhou Metro has successively applied LMIS for Lines 1, 3 and 6 since 2014 to achieve lean maintenance management goals, which include management that is standardized, scientific, lean, and information-based. This system is helpful for building an effective application technology platform for the equipment maintenance in future large-scale line network operations. LMIS allows maintenance operations to be adjusted to meet a management standard, achieve operational guidance and project coordination, and perform monitoring and track results. Moreover, it facilitates data analysis. Comprehensive, detailed records of maintenance job data permit follow-up data analyses and data mining, which provide strong support for the transition of equipment maintenance from a plan-based system to a condition-based one [31].

\subsection{Construction of the Public Relations Crisis Response System}

\subsubsection{Establishing a Crisis Pre-Warning System}

Strategic research on important activities will be performed before the activities are implemented at Guangzhou Metro. Such research includes the strict supervision, identification, classification, and analysis of any early warning about factors that could cause a crisis or the appearance of a crisis. This research will be performed by collecting information about public opinion from print media, network media, television, private media (such as bulletin board systems, microblogs, and service desks), and supervising and analyzing public opinion data from special events.

\subsubsection{Establishing a Crisis Classification System}

Crises are divided into four levels: social discussion, mainstream media involvement, network media involvement, and opinion leader involvement. Guangzhou Metro prejudges and evaluates each crisis and provides disposition rights and coping strategies for different levels of crises.

\subsubsection{Attention to Passengers' Right to Know and to be Appeased}

Guangzhou Metro has been focusing on effectively navigating communication channels. When fault-related delays or other unforeseen circumstances occur, Guangzhou Metro informs passengers of relevant information through traditional broadcasting, notices and the passenger information display system in a timely fashion; in addition, it satisfies passengers' right to know through high-tech communication platforms including a mobile phone app, a microchannel, microblogging, radio, and television [32, 33].

Many humanized measures have been launched in response to passengers' demands when operation faults occur, such as offering free tickets, establishing waiting areas where passengers can wait for connections to public transport, printing emergency bus schedules and establishing green channels to help passengers who need to catch a plane, train or long-distance bus. 


\subsubsection{Enhancing Communications and Co-Construction}

To enhance communication between the metro company and social institutions and the public, Guangzhou Metro has developed colorful communication and co-construction activities with the public, e.g., communicating with passengers by organizing metro afternoon teas, station manager reception days, and open metro days, which advocate traveling politely and safely to help more citizens "enjoy, understand and be able to use the metro service," and by organizing regular communication and co-construction activities with the Guangzhou Disabled Persons' Federation, community neighborhoods and the metro branch of the public security bureau.

\subsection{Attention to the Construction of an Information System for Network Operation}

New requirements for network operation management have been continuously proposed; operation management must be improved via information tools. Guangzhou Metro has widely adopted information tools to build an urban rail transit enterprise with a normative governance structure, an effective management system, a healthy financial structure and industry-leading project management, operation services, technological innovation, and profitability.

\subsubsection{Scientifically Establishing a Top-Level Information System}

Urban rail transit operation management involves passenger transport service, equipment quality management, enterprise operation management, staff management, and other aspects. With the rapid development of IT technology, information systems should account for the fundamental needs of operation management, and focus on management philosophies and goals for network operations; only after such consideration should a top-level information system be developed.

Along with the network operation and management modes, Guangzhou Metro follows a research work flow for information technology. Through a strong business-oriented awareness based on an operation and management strategy, a business-focused information system is established, which includes an information management and control mode and the overall planning, development, and application of information technology maintenance and optimization. Operation management and control objectives can be achieved by strengthening the system's architecture, integrating capacity and introducing a mature and advanced technology platform.

\subsubsection{Overall Planning and Step-by-Step Implementation of the Information System}

During the construction of the information system, Guangzhou Metro insists on a strategy plan that supports strategy and business and readjusts its informatization process gradually; in contrast, enterprise promotes the construction of information systems through overall planning and step-by-step implementation and builds the necessary information management system gradually in four layers: a business management layer, a channel access layer, a management support layer, and a decision support layer. At present, Guangzhou Metro has planned nearly 100 management information systems that cover each key aspects of network operations management. Guangzhou Metro implements unified maintenance and resource sharing to ensure the stability of its information systems and performs the management functions of guaranteeing stability, providing efficient management, improving efficiency and promoting development. The general design of the information system is shown in Fig. 6.

\subsubsection{Management Information Systems for Improving Network Operations}

After nearly 10 years of information system construction, Guangzhou Metro has built and used 72 management information systems. Information technology tools and measures are implemented throughout the operation management of the entire network and provide various data flows and information flows pertaining to the efficiency of transportation services and to analytic support. Along with the use of various instant messaging tools, these measures provide a strong guarantee of promoting operation management.

1. The collective management ideas of the enterprise decision-making layer are achieved.

The information system applies an enterprise strategy and supports the rapid development of business, achieves integrated management through the use of key links, guarantees the normative operation of the overall enterprise by strengthening group control, and promotes the refinement of operation management by optimizing business systems.

An integrated platform for asset information management is constructed. As asset-intensive enterprises, urban rail transit enterprises use advanced operation equipment and complex techniques. Most of the important equipment is valuable. With the expansion of the rail transit network, these assets becomes larger in scale and more varied in type, which poses a challenge for value increases and maintenance. In this context, Guangzhou Metro has shifted 
Fig. 6 General design of the information system

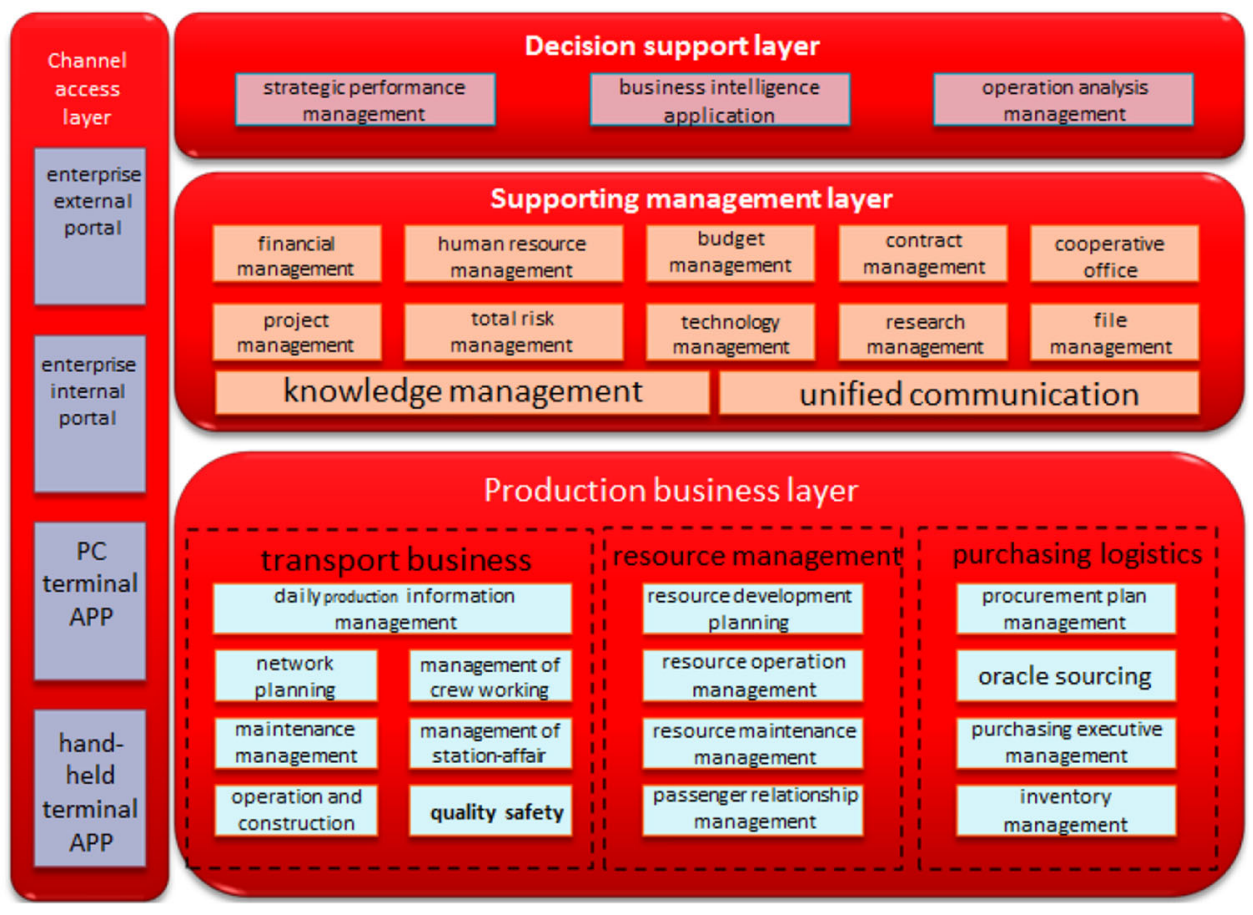

the focus of operation from equipment-operation centered to asset-operation centered. This focus follows the asset life-cycle management and attempts to integrate the management of eight stages (i.e., route design, construction, procurement, acceptance and installation, handover, operation, maintenance, and disposition) and certain functions (i.e., finance, contract, procurement, maintenance, project management, and technical management).

First, the unified classification and its standard of fixed assets are established. In accordance with accounting rules, Guangzhou Metro proposes four principles for compiling a fixed asset catalog: stability, independent utility, similar life cycles, and significance. Meanwhile, to complement the references of national standards and industry classifications, Guangzhou Metro developed a fixed asset catalog with 14 main types, 93 s-tier types, and 381 third-tier types, which has become the standard language for enterprises and systems. The catalog unifies various management standards, including contracts, delivery, using fixed assets, and fixed asset granularity for crucial nodes, resulting in improved data quality.

Second, the asset management process is optimized. Guangzhou Metro considers that six abilities must be developed for integrated asset management: asset investment strategy ability based on integrated considerations, standard management ability, the ability to provide maintenance and extend the life of the asset, cost control ability, internal control ability based on risk management, and transparent information-sharing ability. Based on these six key abilities, the management and process optimization of asset-related management modules (including finance, contracts, projects, operation, and maintenance) are implemented to allow construction, maintenance, and finance to reach agreements regarding asset management and confirm the transparency and standards of the entire operation chain during the asset life-cycle management process.

Third, an integrated system for asset information management is established. A detailed asset life-cycle management scheme is developed, including different service functions (e.g., project initialization management, contract management, a procurement plan, materials management, project settlement, physical transfer, turning supplies into fixed assets, servicing and maintenance, and asset retirement). Meanwhile, the corresponding information system modules are established to effectively support the management of the asset life cycle, solidify the standard service process, and connect different function modules, resulting in collaborative management.

2. The operational efficiency of management is improved.

Information systems provide a collaborative work platform, a convenient business system, and high-efficiency communication tools.

In terms of passenger services, Guangzhou Metro has successively developed Android-based and IOS-based mobile apps, an official We-Chat account, and an official website. These measures not only offer an information platform for passengers' travel needs but also provide more 
effective means for passengers to communicate and for the development of related business.

Example 1: Smartphone App Guangzhou Metro's smartphone app has completed its second phase of construction. In addition to its original functions, such as metro line inquiry, station information, street scenes at exits, and public service information, the app adds many practical functions, such as photo-realistic navigation and interactions. There are approximately one million users; to date, $35 \%$ of these are 30-day active users.

Regarding internal management, four dimensions are involved in the application of operation management information: production scheduling, information communication, equipment quality management, and asset management. Regarding production scheduling and information communication, Guangzhou Metro greatly improves the efficiency of information sharing and communication by using Glink, which is a self-developed mobile terminal communication app.

Example 2: Glink The operation management application functions of the Glink system are continually developed. To meet enterprise production management's instant messaging needs for internal collaboration, operation management, and system maintenance technicians develop applications that allow enterprise inner management to function dynamically. For instance, technicians have exploited several functions of Glink (e.g., daily operations, the micro e-book, and drawing), which are conductive to mobile office management and improve the application of operation data information.

The Glink system provides platform-level functions, such as instant messaging, message alerts, a cooperative office, a dynamic work log and an enterprise address book and effectively handles complex malfunctions and dispatches information via words, figures, and voice, this reducing the misjudgment of malfunctions and dispatching mistakes. In addition, the system provides daily system mobility and ensures the privacy of internal information. Figure 7 presents the special columns that have been implemented to date.

The development and application of the Glink system combines Guangzhou Metro's internal business message with industry-leading technology and meets the requirement of instant contact for staff, provides a rapid and stable platform for transmitting operation safety information, and provides an important mobile portal through which enterprises can post important messages and staff can learn enterprise-related information.

3. Advanced risk-prevention tools are provided.

An honest risk prevention information system is formed using normative and transparent workflow tools and strict permission settings provided by the information system.

4. Significant economic benefit is created.

The extensive application of an information technology system to key actions, including expense control, central management of funds, and Oracle sourcing, improves business efficiency and effectively reduces production and management costs.

\section{Conclusions}

The successively increasing scale of urban rail transit lines gives rise to a shift from a quantitative to qualitative focus in operation management. As a result, conventional operation management methods cannot satisfy the needs of network operation management. Therefore, it is necessary to analyze and study system management methods and to take action from the viewpoint of urban development. This study systematically proposes the mechanisms of innovative network operation management, the creation of the management foundation of a network operation system and staff training, the planning, and preparation of network operation services with advanced capabilities, the strengthening of risk control and emergency system networks, the establishment of an evaluation system and a refined maintenance system to promote the operation of an equipment quality management network, the creation of a public relation crisis response system within the operation network, and improvements in the efficiency and level of operation management through the construction of an information-based operations system.

The congruent relationship between challenges and countermeasures are listed as below (Table 1).
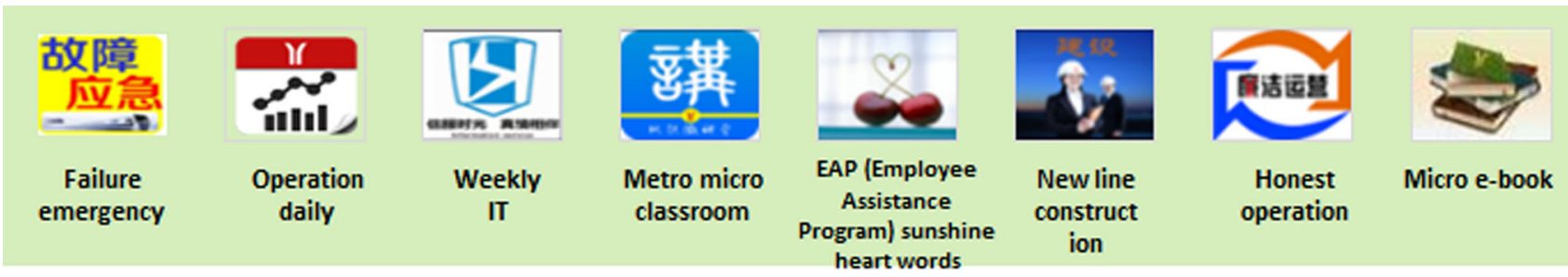

Fig. 7 Special columns applied in the Glink System 
Table 1 The congruent relationship between challenges and countermeasures

\begin{tabular}{|c|c|c|c|}
\hline \multirow[t]{2}{*}{ Potential solutions } & \multicolumn{3}{|c|}{ Challenges } \\
\hline & IPTD & ITDF & NNLO \\
\hline \multicolumn{4}{|l|}{ Innovation of network operation systems and mechanisms } \\
\hline Effective allocation of operation management pressure & & & $\checkmark$ \\
\hline Promoting service responsibility delivered to the primary-level organization & & & $\boldsymbol{\sim}$ \\
\hline Creating the mechanism for "Overall planning and all-round consideration, moderate competition" & & & $\boldsymbol{\sim}$ \\
\hline Establishing a front-end and back-end maintenance system & & & $\boldsymbol{\sim}$ \\
\hline \multicolumn{4}{|l|}{ Promoting the planning of network operations } \\
\hline Comprehensive passenger flow forecasting according to urban development & $\checkmark$ & $\checkmark$ & \\
\hline Innovations in rail operations based on different situations & $\checkmark$ & & \\
\hline Increasing transport capacity through equipment renovation & & $\checkmark$ & \\
\hline Establishing the comprehensive assessment system for transportation manufacturing services & & & $\boldsymbol{V}$ \\
\hline \multicolumn{4}{|l|}{ Strengthening security risk management and the control of network operations } \\
\hline Establishing a full-coverage safety management system & & & $\boldsymbol{V}$ \\
\hline Establishing a quantifiable safety assessment system & & & $\checkmark$ \\
\hline Strengthening safety risk identification and implementing dynamic classified control and prevention & & & $\boldsymbol{\sim}$ \\
\hline Improving the emergency management system & & & $\boldsymbol{V}$ \\
\hline \multicolumn{4}{|l|}{ Promoting the quality management of equipment at the network level } \\
\hline Establishing an equipment quality assessment index & & & $\boldsymbol{V}$ \\
\hline Implementation of lean maintenance management & & & $\boldsymbol{\sim}$ \\
\hline \multicolumn{4}{|l|}{ Construction of the public relations crisis response system } \\
\hline Establishing a crisis pre-warning system & $\checkmark$ & $\checkmark$ & \\
\hline Establishing a crisis classification system & & & $\boldsymbol{\sim}$ \\
\hline Attention to passengers' right to know and to be appeased & $\checkmark$ & & \\
\hline Enhancing communications and co-construction & $\checkmark$ & & \\
\hline \multicolumn{4}{|l|}{ Attention to the construction of an information system for network operation } \\
\hline Scientifically establishing a top-level information system & & & $\boldsymbol{\sim}$ \\
\hline Overall planning and step-by-step implementation of the information system & & $\boldsymbol{V}$ & \\
\hline Management information systems for improving network operations & & & $\checkmark$ \\
\hline
\end{tabular}

IPTD Increasing Public Travel Demand leads to great challenges to operations and management

ITDF Inaccurate Travel Demand Forecasting causes insufficient supply

$N N L O$ New characteristics of Network-Level Operations present challenges to existing management systems

These proposals have been effectively applied to the network's operation management and have resulted in an increased competitive effect. This research and these practices not only ensure the sustainable development of urban rail transit network operations, but also facilitate the qualitative leap for operations management.

Acknowledgments This paper was supported by the Subprogram of National Key Technology, the Support Program of China (2006BAG02B01-07). We greatly appreciate the constructive comments and help from Dr. Jiangtao Liu at Arizona State University in USA and Dr. Kai Lu at Beijing Jiaotong Univerisity in China.

Open Access This article is distributed under the terms of the Creative Commons Attribution 4.0 International License (http://crea tivecommons.org/licenses/by/4.0/), which permits unrestricted use, distribution, and reproduction in any medium, provided you give appropriate credit to the original author(s) and the source, provide a link to the Creative Commons license, and indicate if changes were made.

\section{References}

1. Bureau of Statistics of Guangzhou (2013) Guangzhou statistical yearbook of 2013. China Statistics Press, Beijing

2. Liu M (2014) Public transportation proportion of Beijing reached $46 \%$ in 2013. Beijing Daily: 2014-1-16(6)

3. Zhang C, Li C, He LX, Li J (2014) Statistics and analysis of urban rail transit lines in China. Urban Rapid Rail Transit 28(1):1-3

4. Laporte G, Mesa JA (2015) The design of rapid transit networks, location science. Springer Verlag International Publishing, Berlin, pp 581-594

5. Cortés C, Pagès L, Jayakrishnan R (2005) Microsimulation of flexible transit system designs in realistic urban networks. Transp Res Rec 1923:153-163. doi:10.3141/1923-17 
6. Shi Z (2010) Let technology leads the sustainable development of urban rail transit of China. Urban Rapid Rail Transit 23(1):1

7. Van Oort N (2011) Service reliability and urban public transport design. Dissertation, Delft University of Technology, TRAIL thesis series

8. Schmöcker J, Cooper S, Adeney W (2005) Metro service delay recovery: comparison of strategies and constraints across systems. Transp Res Rec 1930:30-37. doi:10.3141/1930-04

9. Shen J (2007) Network planning and passenger flow prediction for urban rail transit. Urban Rapid Rail Transit 1:2-6

10. Shi H, Sun Y (2012) Characteristics and problems of passenger flows in Guangzhou Rail transit network operation. Urban Rapid Rail Transit 3:29-33

11. Zhu H (2008) Construction of Shanghai urban rail networking operation system. Urban Mass Transit 10:1-5

12. Wang B, Chen D, Yang J (2010) Discussion on network operation of Beijing urban rail transit. Transition 4:14-17

13. He L, Li H, Fang S (2014) Organization system of urban rail transit network operation. Urban Mass Transit 2:1-3

14. Vuchic VR (2005) Urban transit: operations, planning, and economics. Wiley, Hoboken

15. Carrel A, Mishalani RG, Wilson NHM, Attanucci JP, Rahbee AB (2010) Decision factors in service control on a high-frequency metro line and their importance in service delivery. Transp Res Rec 2146:52-59

16. Lv L, Li W, Wen X, Tan R, Zhi D (2015) Methods for forecasting short-term urban mass transit passenger flow. Urban Rapid Rail Transit 28(2):21-25

17. Shen J (2007) Analysis of passenger flow prediction and design of operation organization. Urban Rapid Rail Transit 20(3):3-7

18. Koutsopoulos H, Wang Z (2015) Simulation of urban rail operations: application framework. Transp Res Rec 2006:84-91. doi:10.3141/2006-10

19. Liang Q (2014) Research on unbalanced traffic organization in the peak hour of urban rail transit and its application. Urban Rapid Rail Transit 4:30-34

20. Xu RH, Li X, Chen JJ (2006) Optimization of routing mode on regional express rail. Urban Mass Transit 5:36-39
21. Shafahi Y, Khani A (2010) A practical model for transfer optimization in a transit network: model formulations and solutions. Transp Res Part A Policy Pract 44(6):377-389

22. Vansteenwegen P, Van Oudheusden D (2007) Decreasing the passenger waiting time for an intercity rail network. Transp Res Part B 41:478

23. Zhou Y, Zhou L, Yue Y (2011) Synchronized and coordinated train connecting optimization for transfer stations of urban rail networks. J Railw. 33(3):9

24. Landex A, Nielsen OA (2008) Methods to estimate railway capacity and passenger delays. Department of Transport, Technical university of Denmark

25. Abkowitz M, Tozzi J (1987) Research contributing to managing transit service reliability. J Adv Transp 21:47-65

26. Abkowitz M, Engelstein I (1984) Methods for maintaining transit service regularity. Transp Res Rec 961:1-8

27. O'Dell S, Wilson NHM (1999) Optimal real-time control strategies for rail transit operations during disruptions. In: Wilson NHM (ed) Computer-aided scheduling of public transport. Lecture notes in economics and mathematical systems, vol 471. Springer, Berlin, pp 299-323

28. Levinson HS (2005) The reliability of transit services: a historical perspective. J Urban Technol 12:99-118. doi:10.1080/10630730 500116735

29. Muller T, Furth $P$ (2001) Trip time analyzers: key to transit service quality. Transp Res Rec 1760:10-19. doi:10.3141/1760-02

30. Hensher DA, Prioni P (2002) A service quality index for areawide contract performance assessment. J Transp Econ Policy 36(1):93-113

31. Li H (2015) Refinement and construction of information system for operation maintenance management in Guangzhou Metro. Urban Rapid Rail Transit 28(2):6-10

32. Cats O, Koutsopoulos H, Burghout W, Toledo T (2011) Effect of real-time transit information on dynamic path choice of passengers. Transp Res Rec 2217:46-54. doi:10.3141/2217-06

33. Cats O, Dynamic modelling of Transit operations and passenger decisions. Dissertation, Stockholm: KTH Royal Institute of Technology 